\title{
TLR9 agonists induced cell death in Burkitt's lymphoma cells is variable and influenced by $T L R 9$ polymorphism
}

\author{
J Noack $^{1,2}$, M Jordi $^{1,2}$, L Zauner ${ }^{1,2}$, D Alessi ${ }^{1,2}$, A Burch $^{1,2}$, M Tinguely $^{3}$, M Hersberger $^{2,4}$, M Bernasconi $^{1,2,5}$ and D Nadal ${ }^{\star, 1,2,5}$
}

Toll-like receptor 9 (TLR9) triggering is a promising novel strategy to combat cancer as it induces innate and adaptive immunity responses. B-cell lymphoma is unique in this context as tumor cells express TLR9 and may harbor latent Epstein-Barr virus (EBV), a gamma-herpesvirus with remarkable oncogenic potential when latent. Latent EBV may be promoted by TLR9 triggering via suppression of lytic EBV. Here, we elaborated an initial assessment of the impact of TLR9 triggering on EBV-positive and EBV-negative B-cell lymphoma using Burkitt's lymphoma (BL) cell lines as an in vitro model. We show that, independent of the presence of EBV, the TLR9 ligand oligodeoxynucleotide (ODN) CpG-2006 may or may not induce caspase-dependent cell death in BL cells. Moreover, ODN CpG-2006-induced cell death responses of BL cells were associated with TLR9 single-nucleotide polymorphisms (SNPs) rs5743836 or rs352140, which we detected in primary BL tumors and in peripheral blood from healthy individuals at similar frequencies. Thus, our findings suggest that the effect of TLR9 agonists on BL cells should be tested in vitro before installment of therapy and TLR9 SNPs in BL patients should be determined as potential biological markers for the therapeutic response to treatment targeting innate immunity.

Cell Death and Disease (2012) 3, e323; doi:10.1038/cddis.2012.60; published online 21 June 2012

Subject Category: Cancer

Toll-like receptors (TLRs) are important players of the innate immune system, ${ }^{1}$ and expression of the 10 TLRs known in humans ${ }^{2,3}$ depends on the cell subset and differentiation status. ${ }^{4-6}$ TLR9 is preferentially expressed by B cells and plasmacytoid dendritic cells (reviewed in reference Iwasaki and Medzhitov ${ }^{1}$ ). Synthetic TLR9 ligands, short oligodeoxynucleotides (ODN) with unmethylated CpG motifs, ${ }^{7}$ activate TLR9 that recruits the adapter protein myeloid differentiation factor 88 (MyD88) and induces a cascade leading to the nuclear translocation of the transcription factor nuclear factor kappa-light-chain-enhancer of activated B cells (NF- $\kappa \mathrm{B}){ }^{2}$

The immune response following TLR9 engagement is highly desirable for cancer treatment. ${ }^{8}$ Synthetic TLR9 agonists are regarded as potential anti-cancer agents. Clinical trials have shown promising results for the treatment of various cancer types with CpG ODNs. ${ }^{9}$ Their effects can be indirect by enhancing the anti-tumor immune response or direct by inducing apoptosis in the malignant cells. Direct effects would be expected for B-cell malignancies as they express TLR9. B-cell activation can eventually lead to activation-induced cell death of cancer cells and therefore support anti-cancer treatment. ${ }^{10}$ Nevertheless, the TLR9 agonist effects vary strongly between B-cell cancer types, and the responses of B-cell lymphomas to ODN CpG-2006 show high variability. ${ }^{11}$ Thus, the effects of CpG ODNs on B-cell malignancies are not predictable. Moreover, CpG ODN treatment has tumor-promoting effects on benign $B$ cells and strongly enhances their proliferation and differentiation. ${ }^{12-14}$

Stimulation of TLR9 with ODN CpG-2006 suppresses lytic reactivation of Epstein-Barr virus (EBV), a B-cell tropic gamma-herpesvirus, and can thereby promote latent EBV. ${ }^{15,16}$ The latter is associated with several types of B-cell lymphomas including Burkitt's lymphoma $(\mathrm{BL}){ }^{17} \mathrm{EBV}$ is present in nearly all cases of the high-incidence form of $B L$ ('endemic BL'), in up to $85 \%$ of the intermediate-incidence cases, and in $15 \%$ of the low-incidence cases ('sporadic' BL). Up to $40 \%$ of $B L$ in human immunodeficiency virus carriers harbor EBV. ${ }^{17}$ As latent $\mathrm{EBV}$ exhibits unique growth transformation potential on $B$ cells in vitro ${ }^{18}$ and TLR9 triggering enhances EBV-induced B-cell transformation ${ }^{19}$ and promotes latent EBV in vitro, ${ }^{15,16}$ TLR9 stimulation in the treatment of EBV-positive BL could provoke detrimental rather than beneficial outcomes.

\footnotetext{
${ }^{1}$ Experimental Infectious Diseases and Cancer Research, Division of Infectious Diseases and Hospital Epidemiology, University Children's Hospital of Zurich, Zurich, Switzerland; ${ }^{2}$ Children's Research Center, University Children's Hospital of Zurich, Zurich, Switzerland; ${ }^{3}$ Institute of Surgical, Pathology, University Children's Hospital of Zurich, Zurich, Switzerland and ${ }^{4}$ Division of Clinical Chemistry and Biochemistry, University Children's Hospital of Zurich, Zurich, Switzerland

${ }^{*}$ Corresponding author: D Nadal, Division of Infectious Diseases and Hospital Epidemiology, University Children's Hospital of Zurich, Steinwiesstrasse 75, Zurich CH-8032, Switzerland. Tel: +41 44266 7250; Fax: +41 44266 8072; E-mail: david.nadal@kispi.uzh.ch

${ }^{5}$ These authors contributed equally to this work.

Keywords: Burkitt's lymphoma; Epstein-Barr virus; Toll-like receptor TLR 9 agonists; polymorphism; CpG

Abbreviations: BL, Burkitt's lymphoma; Ct, Cycle threshold; EBV, Epstein-Barr virus; hlL-10, human interleukin 10; MFI, mean fluorescence intensity; MyD88, myeloid differentiation factor D 88; NF- $\kappa$ B, nuclear factor kappa-light-chain-enhancer of activated B cells; ODN, oligodeoxynucleotide; PBS, phosphate-buffered saline; qRT-PCR quantitative real-time polymerase chain reaction; rhIL-10, recombinant human interleukin 10; TLR, Toll-like receptor

Received 13.12.11; revised 24.4.12; accepted 02.5.12; Edited by H-U Simon
} 
Single-nucleotide polymorphisms (SNPs) of TLR9 are associated with increased risk for certain B-cell lymphomas ${ }^{20}$ and have the potential to exhibit deregulation of signaling thereby promoting tumorigenesis. The responses of TLR9 SNPs in B-cell tumors to CpG ODN treatment are not reported.

Here, we used BL-cell lines to model direct effects of TLR9 stimulation on malignant cells, investigate the influence of EBV, and assess the impact of TLR9SNPs, which we found in primary $\mathrm{BL}$ samples or in healthy primary cells.

\section{Results}

TLR9 triggering alters gene expression and activates Akata cells in a MyD88-dependent manner. CpG ODNs activate $B$ cells by impacting on gene expression. ${ }^{21} \mathrm{We}$ asked how the gene expression pattern of BL cells is affected by TLR9 triggering using CpG ODN. We performed a microarray analysis comparing ODN CpG-2006-treated versus untreated Akata cells. Most of the $\geq 2$-fold changes in gene expression were upregulation and only few downregulation. Among upregulated genes, we were mainly interested in those involved in cytokine (human interleukin $10 ; h / L-10)$ and chemokine expression (CXCL10), B-cell activation $(C D 40)$, transcription $(N F-\kappa B)$ and apoptosis (FAS) as these genes are those that preferentially determine cell proliferation and survival (Supplementary Table 1). Thirteen genes, including two regulating cell cycle, one transcription factor, one involved in B-cell differentiation and apoptosis, four of diverse functions and four of unknown function, showed downregulation following ODN CpG-2006 treatment (Supplementary Table 2).

We earlier confirmed that TLR9 triggering of Akata cells with ODN CpG-2006 increases hIL-10 expression and leads to the translocation of NF- $\kappa \mathrm{B}$ to the nucleus. ${ }^{16}$ To validate a marker for B-cell activation, in this context, we measured CD40 expression by flow cytometry. CD40 expression was increased upon ODN CpG-2006 treatment (Figure 1a). After $48 \mathrm{~h}, \mathrm{CD} 40$ expression on ODN CpG-2006-treated cells was increased 2.7-fold compared with untreated cells (Figures 1a and b). Surprisingly, the control ODN GpC-2006, which is similar to ODN CpG-2006 but lacks the CpG motifs, also led to a 2.4-fold increase in CD40 expression (Figures 1a and b). This might reflect a TLR9-independent mechanism or the ability of the control ODN to stimulate TLR9 in BL cells.

To clarify this point, we used Akata cells overexpressing a dominant-negative mutant of the adaptor protein MyD88 (DN-MyD88). ${ }^{16}$ Treatment with ODN CpG-2006 or ODN GpC-2006 induced increased CD40 expression, corroborating our first observation (Figure 1c). By contrast, neither ODN
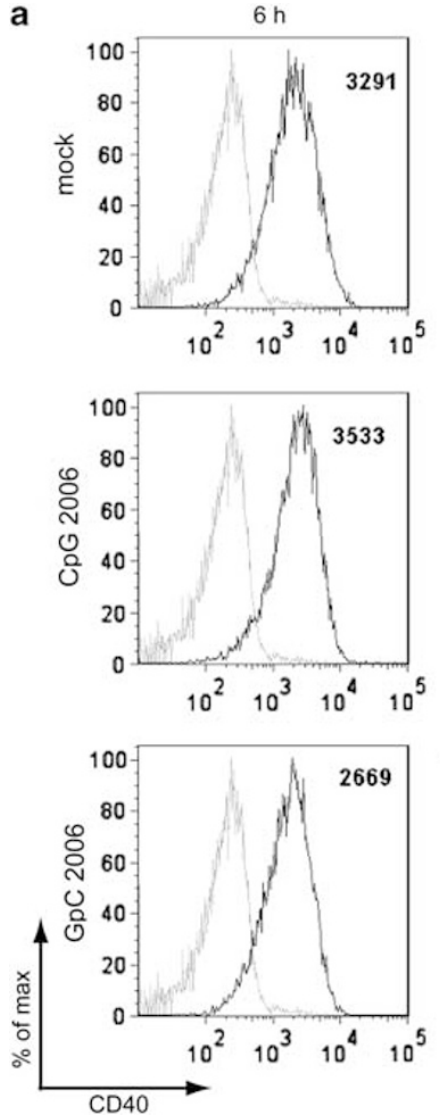
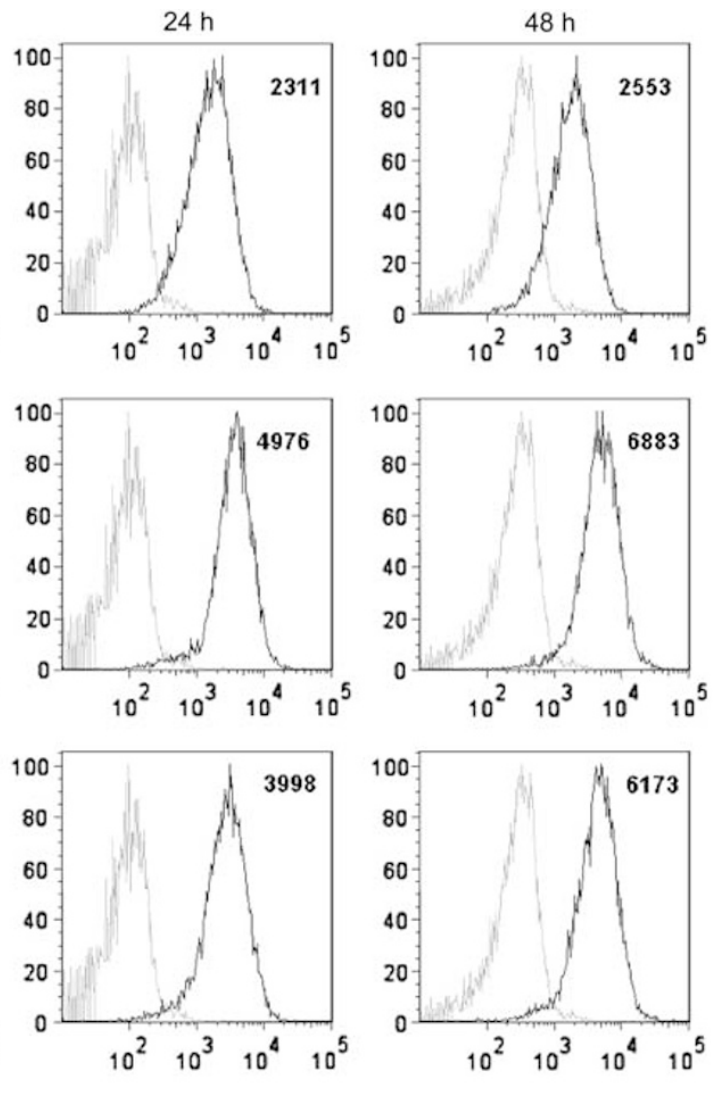

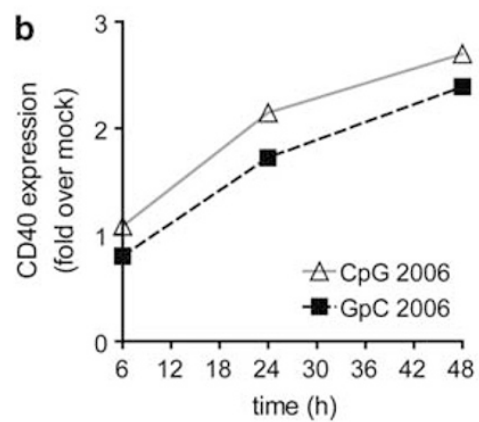

c $\square$ Akata

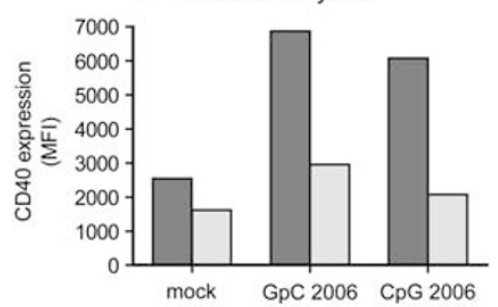

Figure 1 TLR9 agonists induce CD40 expression in Akata cells in a MyD88-dependent manner. Akata cells or DN-MyD88 Akata cells were left untreated or treated with $0.5 \mu \mathrm{M}$ ODN CpG-2006 or ODN GpC-2006 for 48 h. After 6, 24 and 48 h, $10^{5}$ cells were harvested, washed with PBS and stained with PE-Cy5-conjugated mouse anti-human CD40 antibody or a PE-Cy5 mouse IgG1 $\kappa$ isotype control and analyzed with a flow cytometer. (a) FACS plots of Akata cells. Isotype control: shaded gray line; anti-CD40 PE-Cy5: black line. Numbers indicate the mean fluorescence intensity (MFI) (b) Quantification of (a). (c) Comparison of CD40 expression in Akata cells and DN-MyD88 Akata cells 
CpG-2006 nor ODN GpC-2006 significantly induced an increase in CD40 expression in DN-MyD88 Akata cells (Figure 1c). Finally, we validated the ODN CpG-2006 treatment-induced upregulation of STAT3 (Supplementary Table 1) by quantitative real-time polymerase chain reaction (qRT-PCR) and confirmed activation of STAT3 by western blot (data not shown).

Collectively, we validated our microarray data showing that triggering with ODN CpG-2006 activates Akata cells to induce CD40 and STAT3 expression. Moreover, our results indicated that both ODNs used here act in a MyD88dependent manner and that the ODN lacking CpG motifs activates Akata cells to a similar extent as the ODN containing CpG motifs.

TLR9 triggering by CpG ODN does not impact on the cell cycle of Akata cells. TLR9 triggering leads to cell cycle entry and proliferation of $\mathrm{B}$ chronic lymphatic leukemia cells. ${ }^{11,12,22}$ We analyzed the cell cycle of mock-treated or ODN CpG-2006-treated Akata cells after initiation of treatment by propidium iodide staining and flow cytometry. Most cells were in the $S$ phase during the time frame of $48 \mathrm{~h}$ (Supplementary Figure 1). Treatment with ODN CpG-2006 did not alter the cell cycle compared with mock treatment. Similar results were obtained with Akata31 cells (data not shown), an EBV-negative subclone of Akata cells. ${ }^{23}$ Thus, although TLR9 triggering by ODN CpG-2006 resulted in BLcell activation based on increased expression of certain genes, it did not seem to influence the cell cycle.

ODN-induced cell death of BL Akata cells is MyD88dependent. Treatment with ODN GpC-2006 unexpectedly induced CD40 upregulation in Akata cells in a MyD88dependent manner similar to treatment with ODN CpG-2006. We determined whether treatment with distinct TLR9 ligands would similarly result in a MyD88-dependent effect on cell survival. Also, we explored whether a class A ODN, that displays low specificity for B cells, exerts similar effects on BL cells as class B ODNs that possess a high specificity for $B$ cells. Therefore, we treated Akata cells or DN-MyD88 Akata cells with ODN CpG-2216 (type A), ODN CpG-2006 (type B) and ODN GpC-2006 (type B control), respectively, and analyzed the viability of the cells by Trypan Blue exclusion assay and PE-Annexin V/7-amino-actinomycin (7-AAD) staining. The Trypan Blue exclusion assay showed that treatment of Akata cells with ODN CpG-2006 or ODN GpC-2006 reduced the survival of cells within $48 \mathrm{~h}$ to below $50 \%$ of not treated cells and treatment with ODN CpG-2216 to almost $50 \%$ of not treated cells after $72 \mathrm{~h}$ (Figure 2a). By contrast, the survival of DN-MyD88 Akata cells was not, if at all, reduced by treatment with any of the three ODNs for $72 \mathrm{~h}$ (Figure 2a). These findings were corroborated by the Annexin V/7-AAD assay revealing that the viability of Akata cells was drastically affected by treatment with class B ODNs and to a lesser extent with class A ODN, contrasting DN-MyD88 Akata cells that were not affected by treatment with ODNs for $72 \mathrm{~h}$ (Figure $2 \mathrm{~b}$ and quantification in Figure 2c). Thus, treatment of Akata cells with ODNs CpG2006 and GpC-2006 triggers TLR9 signaling via MyD88 and results in cell death.
ODN-induced cell death of BL Akata cells is caspasedependent. To explore the mechanism of ODN-induced cell death of Akata cells we set out to investigate whether caspases were involved. Thus, the activity of caspase-3 and -7 in ODN-treated Akata cells was detected using a luminogenic substrate, which gives rise to a luminescent signal proportional to caspase-3/7 activity. Triggering with TLR9 ligands for $48 \mathrm{~h}$ increased the luminescent signal about twofold as compared with no triggering. This increase was abolished by treatment with the caspase inhibitor z-VADFMK (Figure 3a), indicating that TLR9 triggering resulted in increased caspase activity in Akata cells and that this activity was not increased if cells were concomitantly treated with a caspase inhibitor. These findings were corroborated using PI staining, which indicate that Akata cell death induced by treatment with ODNs can be abrogated by the caspase inhibitor z-VAD-FMK (Figure 3b); and by western blotting showing that PARP cleavage is increased by ODN treatment and can be reduced by the inhibitor (Figure 3c). Thus, ODN-induced cell death of Akata cells was found to be caspase-3/7 dependent and therefore due to apoptosis.

Survival of distinct BL cells following treatment with CpG ODNs differs considerably, independently of the presence of EBV. ODN CpG-2006 suppresses EBV lytic gene expression in Akata cells and primary $B$ cells promoting latent EBV that may provide cell survival signals. ${ }^{15,16}$ As we observed Akata cell death upon TLR9 triggering, we asked whether the absence of EBV would result in even more pronounced cell death following TLR9 triggering. Hence, we tested whether TLR9 agonists affect the survival of EBVpositive Akata cells and of EBV-negative Akata31 cells in a similar fashion. Treatment with ODN CpG-2006 or ODN GpC-2006 strongly decreased the percentages of surviving Akata cells or Akata 31 cells between 24 and $72 \mathrm{~h}$ compared with untreated cells. Nevertheless, the effect on Akata 31 cells was less marked (Figure 4a). The percentages of apoptotic Akata 31 cells assessed by Annexin V/7-AAD staining after $72 \mathrm{~h}$ of treatment, however, were comparable to those of Akata cells (Figure 4b). Treatment with ODN CpG2216, ODN CpG-2006 or ODN GpC-2006 resulted in similar respective decreases in viability of Akata cells versus Akata31 cells due to apoptosis. Treatment with class A ODN CpG-2216 exhibited almost no negative impact on cell survival compared with treatment with the class B ODNs CpG-2006 and GpC-2006 (Figure 4b). These results showed that EBV-negative Akata31 cells exhibited a higher level of spontaneous cell death by apoptosis compared with EBV-positive Akata cells and corroborated the lower effect of TLR9 triggering by class A ODN compared with triggering by class $B$ ODNs. Moreover, the results suggested that the presence of EBV does not prevent EBV-positive Akata cells from TLR9 triggering-induced cell death compared with EBV-negative Akata31 cells.

Next, we investigated whether our observations in EBV-positive versus EBV-negative $\mathrm{BL}$ cells hold true in $\mathrm{BL}$ cells other than Akata. To this end, we used EBV-positive BL cells Mutu-I and EBV-negative BL cells BJAB and Ramos. Treatment with ODN CpG-2006 or with ODN GpC-2006 did not affect Mutu-I cell or BJAB cell survival (Figure 4c) but it 

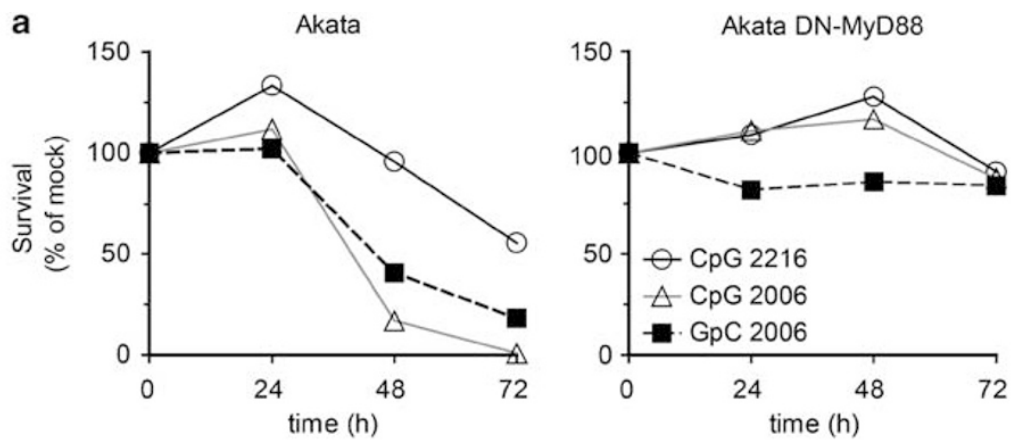

b

mock $\quad$ CpG 2216
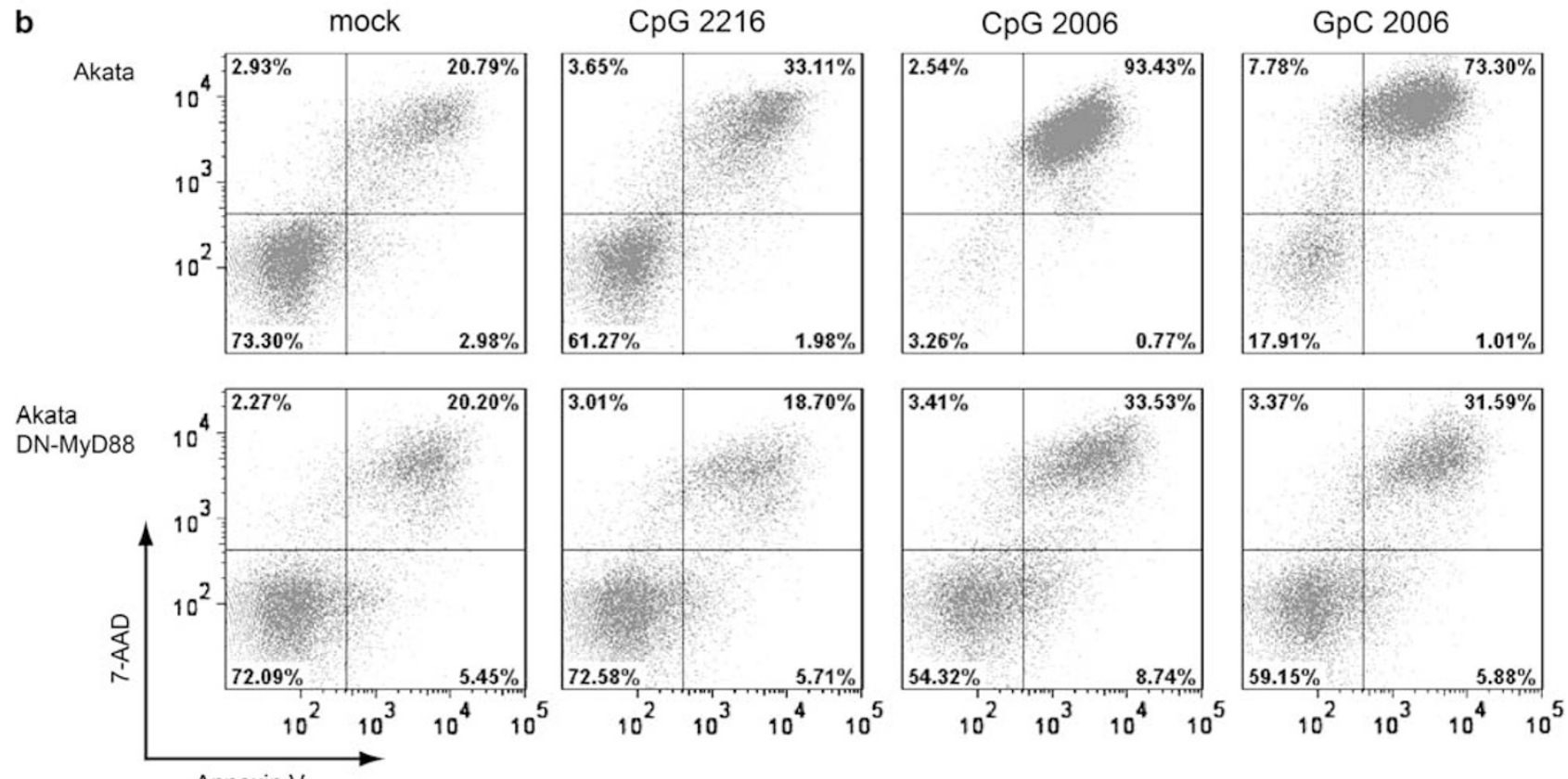

Annexin V
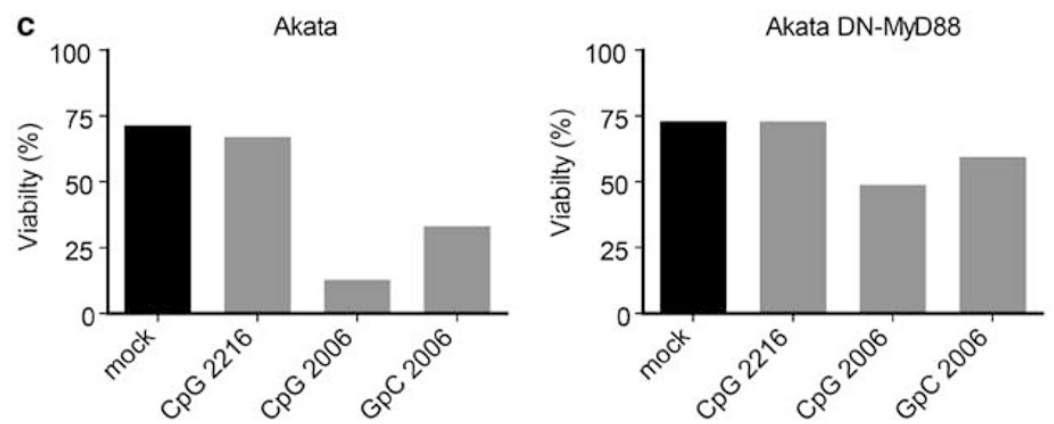

Figure 2 The cell death induced by TLR9 agonists is MyD88 dependent. Akata cells and DN-MyD88 Akata cells were incubated with medium only, ODN CpG-2216, ODN CpG-2006 or ODN GpC-2006. (a) The cell survival was assessed by Trypan Blue exclusion assay 0, 24, 48 and $72 \mathrm{~h}$ after treatment. (b) Apoptosis assay after $72 \mathrm{~h}$ of treatment. $10^{5}$ cells were stained with PE-Annexin V/7-AAD and analyzed by flow cytometry. The double-negative population represents viable cells whereas PE-Annexin V-positive or double-positive populations represent non-viable cells. (c) Quantification of the Annexin V/7-AAD assay in (b). Shown are the results of a representative experiment of two experiments (showing mean values)

decreased Ramos cell survival between 48 and $72 \mathrm{~h}$ (Figure 4c). Thus, the survival of BL cells following TLR9 triggering considerably differs between distinct $B L$ cells and does not seem to depend on the presence or absence of EBV.

Exogenous hIL-10 does not prevent ODN CpG-2006induced cell death. hIL-10 has an important role in B-cell lymphoma biology as it seems to act as autocrine growth factor. $^{22,24-26}$ We previously reported ${ }^{16}$ and corroborate here, a strong hIL-10 induction in Akata cells following TLR9 triggering with ODN CpG-2006 (Supplementary Table 1). Nevertheless, the very same treatment resulted in drastic Akata cell death (Figure 2), suggesting that the latter could not be prevented by the induction of hIL-10 expression. 

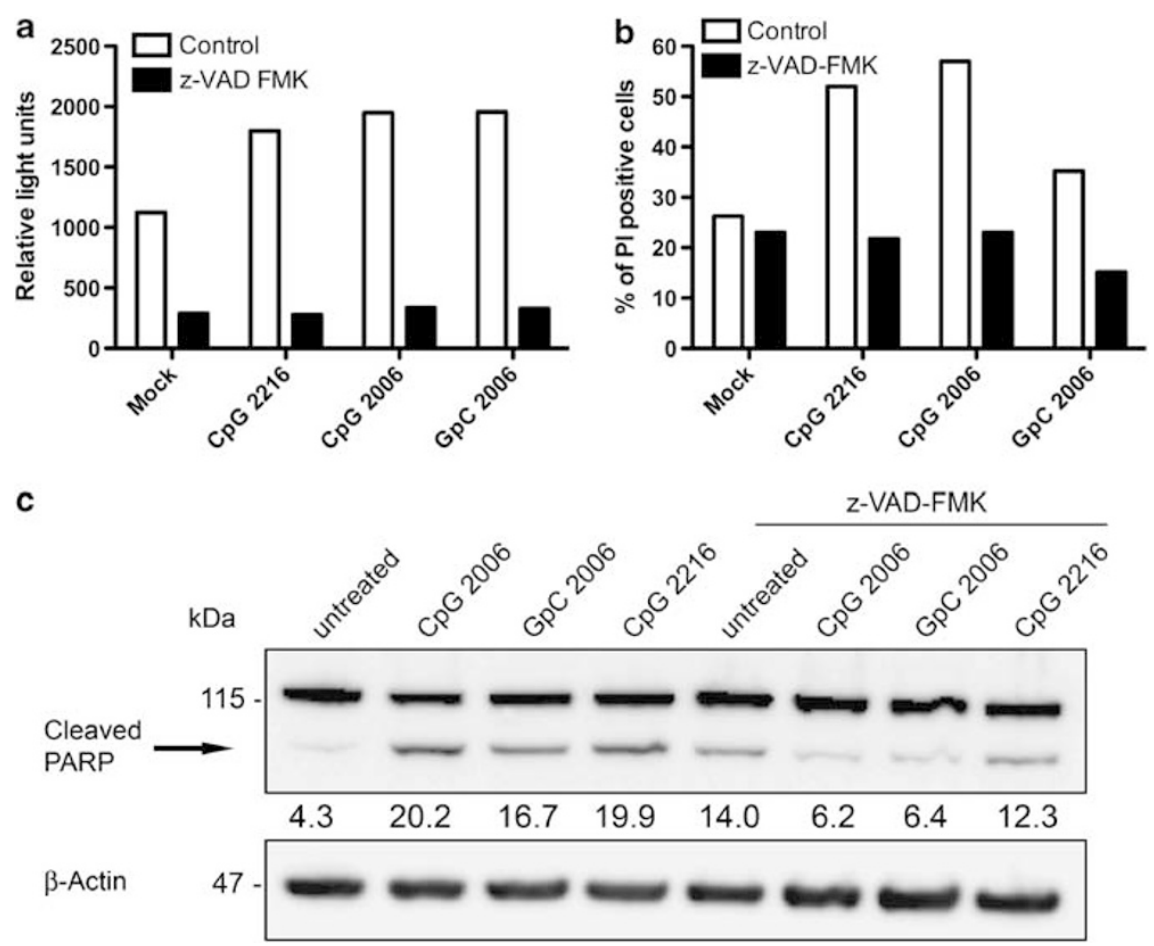

Figure 3 TLR9 ligands induce cell death of Akata cells via caspase activation. (a) Caspase activity in $0.5 \times 10^{6}$ Akata cells measured $48 \mathrm{~h}$ after treatment with the TLR9 ligands ODN CpG-2006, ODN GpC-2006 and ODN CpG-2216 without or with z-VAD-FMK. Cells were incubated with the Caspase-Glo luminogenic substrate to detect activated caspases and analyzed with a luminometer. Results represent the relative light units generated by active caspases 3 and 7 . Shown in the bar graph are the results of a representative experiment out of three performed in duplicate. (b) Treatment of Akata cells with caspase inhibitor z-VAD-FMK reduces TLR9 ligand-induced cell death. $10^{6}$ Akata cells were treated with the TLR9 ligands ODN CpG-2006, ODN GpC-2006 or ODN CpG-2216 with or without addition of z-VAD-FMK. After $48 \mathrm{~h}$, cells were stained with PI and analyzed by flow cytometry. Shown are the results of a representative experiment out of two experiments performed in duplicate. (c) Treatment of Akata cells with TLR9 ligand induces PARP cleavage. Lysates from $10^{6}$ Akata cells $48 \mathrm{~h}$ after incubation with the TLR9 ligands ODN CpG-2216, ODN CpG-2006 and ODN GpC-2006 with or without z-VAD-FMK were analyzed by immunoblotting for PARP cleavage. The relative density of the cleaved PARP was calculated using densitometry and normalized to $\beta$-actin

Otherwise, a recent report suggested that treatment with ODN CpG-2006-induced hIL-10 in chronic lymphocytic leukemia B cells mediating their cell death. ${ }^{10}$ Therefore, we treated Akata cells and DN-MyD88 Akata cells with ODN CpG-2006, recombinant hIL-10 (rhlL-10) or a combination thereof. The concentration of rhIL-10 was based on the peak hIL-10 protein concentration induced by ODN CpG-2006 treatment in Akata cells. ${ }^{16}$ Additionally, ODN CpG-2006 treatment was reiterated at $48 \mathrm{~h}$ in a fraction of $\mathrm{BL}$ cells.

As expected, treatment with ODN CpG-2006 for $72 \mathrm{~h}$ reduced the viability of Akata cells to $<20 \%$ but did not reduce viability of DN-MyD88 Akata cells compared with no treatment (Figures $5 \mathrm{a}-\mathrm{c}$ ). Reiterated treatment with ODN CpG-2006 after 48 h did not further reduce viability of Akata cells compared with one-time treatment and did not reduce viability of DN-MyD88 Akata cells (Figure $5 \mathrm{a}-\mathrm{c}$ ). Treatment with rhlL-10 for $72 \mathrm{~h}$ also did not reduce viability of Akata cells or DN-MyD88 Akata cells compared with no treatment. Treatment with rhIL-10 did not counteract ODN CpG-2006 treatment-induced reduction of $\mathrm{BL}$ cell viability or further decreased their viability. DN-MyD88 Akata cells were not affected by any of the treatments (Figures $5 \mathrm{a}-\mathrm{c}$ ). Thus, maximal negative impact of ODN CpG-2006 on cell survival in Akata cells occurred after one treatment. Moreover, rhIL-10 did not change the number of viable Akata cells, or rescue Akata cells from ODN CpG-2006 treatment-induced cell death. This suggested that hIL-10 cannot counteract TLR9 triggering-induced cell activation resulting in death of Akata cells and is not responsible for their cell death.

BL cells express distinct $h / L-10$ mRNA and hIL-10 levels following TLR9 triggering. The distinct survival of BL cells following TLR9 triggering with ODN CpG could be because of distinct magnitudes of ensuing cellular responses. The induction of hIL-10 following ODN CpG treatment can be regarded as a surrogate marker for the magnitude of cell activation mediated by TLR9 triggering. Thus, we assessed h/L-10 mRNA expression in BL cells treated with ODN CpG-2006 or ODN GpC-2006. All five BL cell lines tested expressed hIL-10 mRNA following treatment with ODN CpG2006 , the values peaking preferentially at $6 \mathrm{~h}$ post treatment (Figure 6a). Peak hIL-10 mRNA expression levels varied from 1.3 transcripts over HMBS in Ramos $\mathrm{BL}$ cells to 48 transcripts in Mutu-I BL cells. Treatment with ODN GpC-2006 also resulted in induction of $h / L-10$ mRNA expression but in lower levels, except in Akata cells. Similar variation of results was observed when analyzing hIL-10 protein levels (Figure 6b). Thus, TLR9 triggering of distinct $\mathrm{BL}$ cells resulted in a broad range of $h / L-10$ mRNA and $\mathrm{hIL-10}$ protein expression levels, and the magnitude of the level seemed independent of EBV status.

Next, we determined TLR9 mRNA expression levels in $\mathrm{BL}$ cells by $q R T-P C R$. Although distinct BL cells showed up to sixfold different relative TLR9 mRNA expression levels 

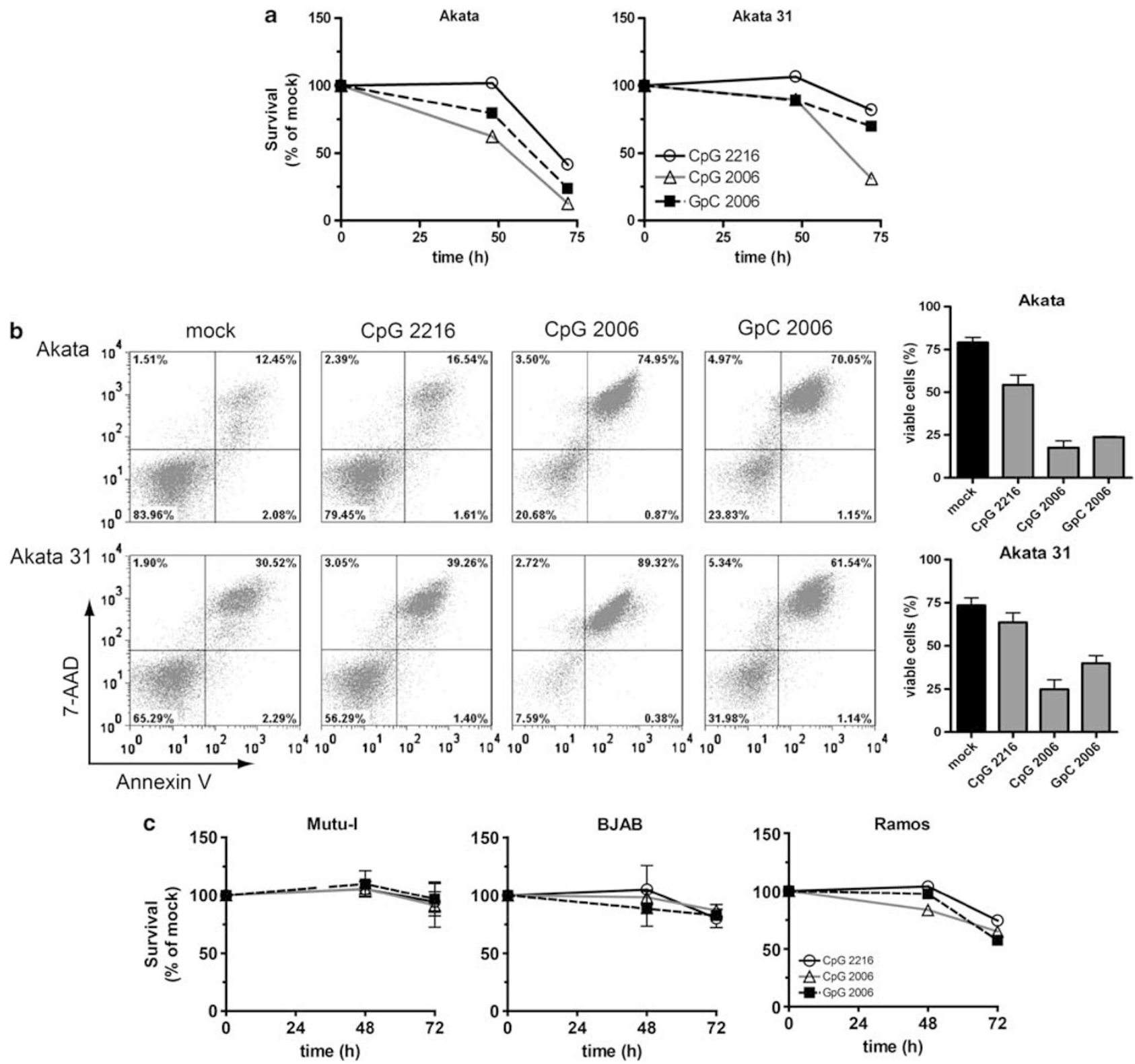

Figure 4 TLR9 agonists induce cell death of Akata cells and Akata31 BL cells, but not of Mutu-I BL cells or BJAB BL cells, while Ramos BL cells are intermediately affected. $10^{6}$ cells were treated with the TLR9 ligands ODN CpG-2216, ODN CpG-2006 and ODN GpC-2006. (a) Survival of untreated, ODN CpG-2006-treated or ODN GpC2006-treated Akata cells and Akata $31 \mathrm{BL}$ cells was assessed by Trypan Blue exclusion assay and counting of viable and dead cells and compared with the untreated control. (b) Apoptosis of Akata and Akata $31 \mathrm{BL}$ cells after $72 \mathrm{~h}$ of treatment. $10^{5}$ cells were stained with PE-Annexin V/7-AAD and analyzed by flow cytometry (left panel); percentages of PE-Annexin V/7-AAD negative cells (right panel). (c) The survival of untreated, ODN CpG-2006 or ODN GpC-2006-treated Mutu-I, BJAB and Ramos BL cells was evaluated by Trypan Blue exclusion. Shown are the results of a representative experiment out of at least two experiments performed in duplicate (showing mean values) or in triplicate (showing mean values \pm S.E.M., indicated by error bars)

(Figure 6c), ODN CpG-2006 treatment-induced $h I L-10 \mathrm{mRNA}$ peak expression levels did not correlate with the relative TLR9 mRNA expression levels (Figure 6d). Collectively, TLR9 triggering in distinct $\mathrm{BL}$ cells resulted in distinct $h / L-10 \mathrm{mRNA}$ expression, not linked to presence or absence of EBV, and not correlated to $T L R 9$ mRNA expression levels.

TLR9 polymorphisms of BL cells might correlate with distinct responses to TLR9 triggering. TLR9 polymorphisms in patients are linked to different outcomes of inflammatory diseases and the development of cancer. ${ }^{27,28}$ We hypothesized that TLR9 polymorphisms could be a possible explanation for our observations. Thus, we isolated the genomic DNA from BL cell lines and analyzed it for the presence of TLR9 polymorphisms. We found specific SNPs for each cell line, allowing segregation of the BL cell lines into three groups (Table 1): -1237 TT/1635 GA (Akata and Akata 31), - 1237 TT/1635 GG (Ramos) and - 1237 TC/1635 GG (Mutu-I and BJAB). This sub-grouping correlated with the degree of BL-cell survival in response to ODN 

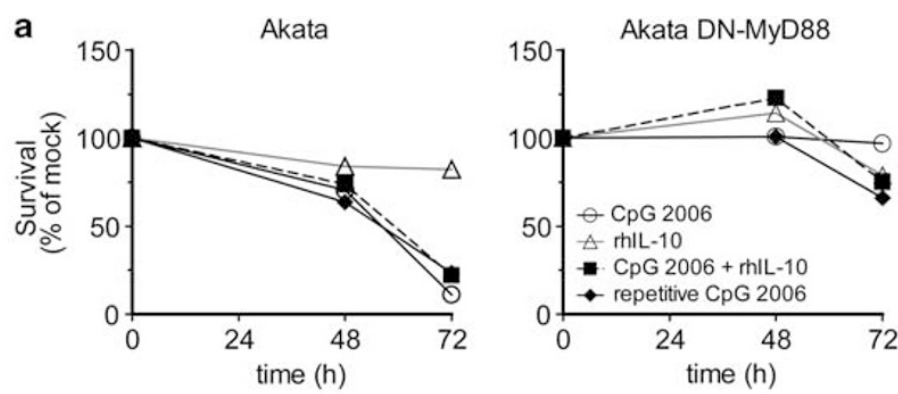

b
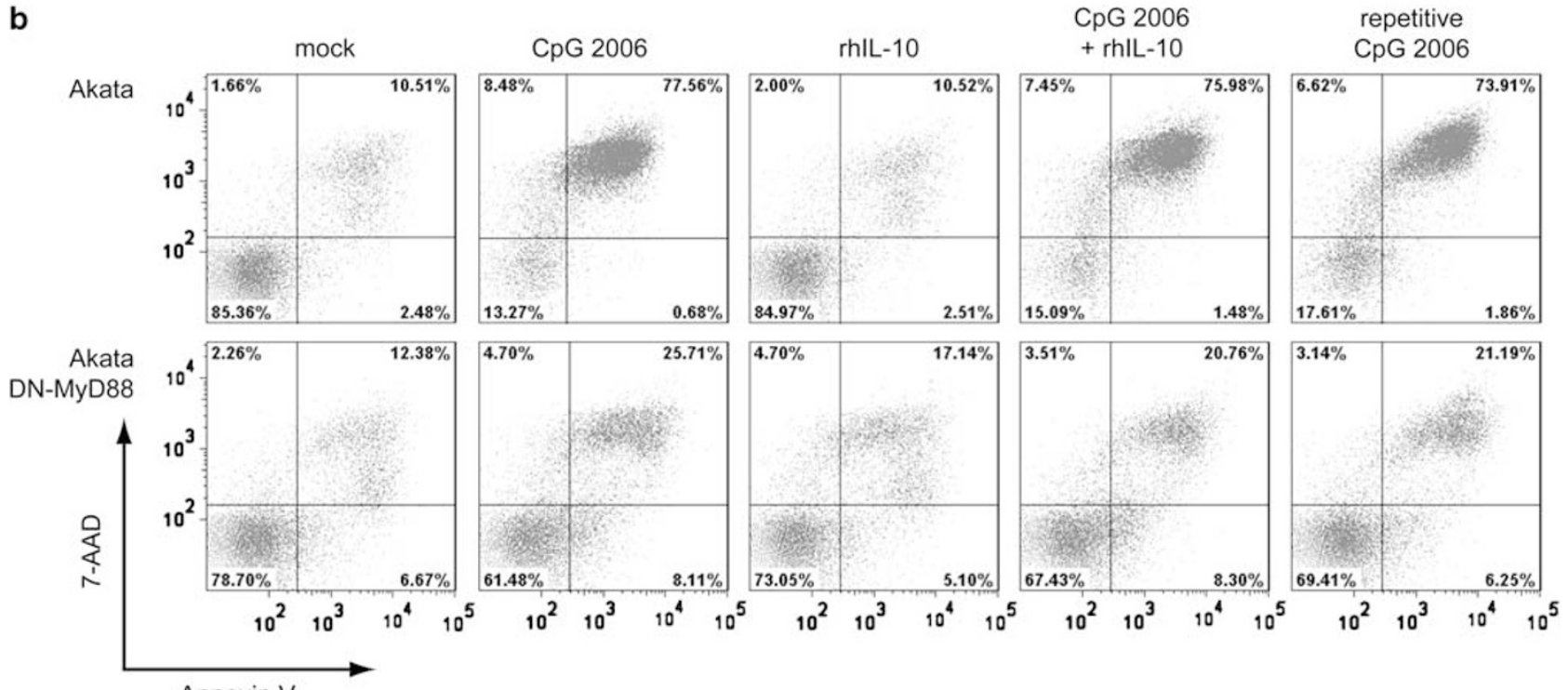

Annexin V

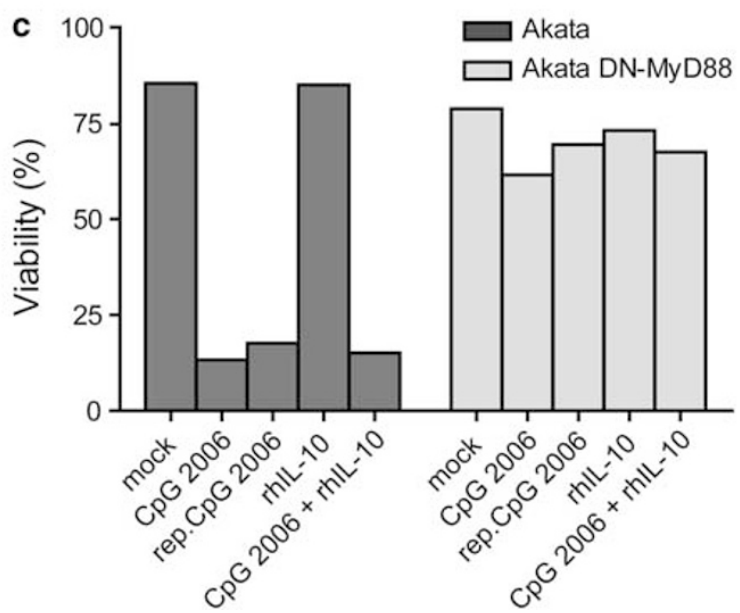

Figure 5 hIL-10 does not influence ODN CpG-2006-induced cell death. Akata cells and DN-MyD88 Akata cells were incubated with medium only, $0.5 \mu$ M ODN CpG-2006, $900 \mathrm{pg} / \mathrm{ml} \mathrm{rhlL-10}$ or combination of ODN CpG-2006 and rhlL-10. To one ODN CpG-2006-stimulated sample, $0.5 \mathrm{mM}$ ODN CpG-2006 was added again after $48 \mathrm{~h}$ (rep. CpG2006). (a) The cell viability was monitored by the Trypan Blue exclusion test 0,48 and $72 \mathrm{~h}$ after treatment. (b) After $72 \mathrm{~h}$ cells were harvested and $10^{5}$ cells were stained with PE-Annexin V/7-AAD and analyzed by flow cytometry. (c) Quantification of (b)

treatment (Figure 4c), suggesting that the distinct BL-cell responses to TLR 9 triggering may depend on the SNPs present.

Next, we analyzed TLR9 SNPs in genomic DNA from primary BLs or blood from healthy individuals. Indeed, we found the TLR9 SNPs detected in our BL cell lines in primary $\mathrm{BL}$ samples and blood of healthy individuals
(Table 2). Importantly, the TLR9 SNP frequencies were statistically not significantly different between BL cell lines, primary BLs and blood from healthy individuals, respectively. This suggested that if the direct response to TLR9 agonists depends on the TLR9 SNP, this could be an important factor regarding the treatment of $B L$ patients by TLR9 triggering. 

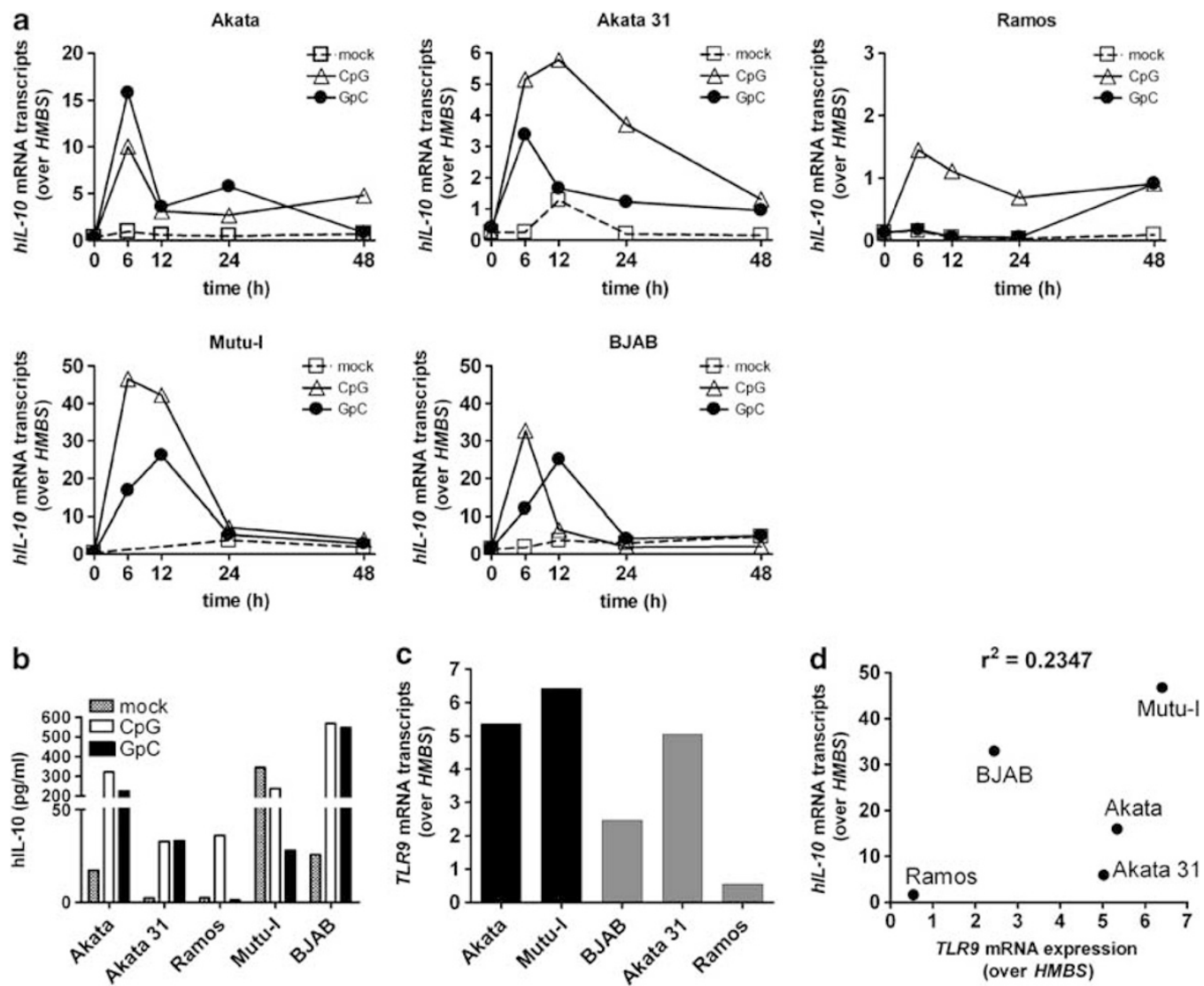

Figure 6 Treatment of BL cell lines with TLR9 agonists induces distinct $h / L-10 \mathrm{mRNA}$ and hIL-10 expression levels. (a) TLR9 triggering results in a wide range of $h / L-10$ mRNA expression levels. BL cells were left untreated or treated with $0.5 \mu \mathrm{M}$ ODN CpG-2006 or ODN GpC-2006 for the indicated time points. (b) hIL-10 protein expression levels in the culture supernatants of BL cell lines $6 \mathrm{~h}$ after treatment or no treatment as in (a) measured by ELISA. (c) TLR9 mRNA expression levels differ between BL cell lines by up to sixfold. EBV-positive (black bars) and EBV-negative (gray bars) BL cells. (d) The hlL-10 mRNA peak expression responses to ODN CpG-2006 did not correlate with the corresponding relative TLR9 mRNA levels. Total RNA of $10^{6}$ cells was isolated and transcribed into CDNA. HMBS, $h I L-10$ or TLR9 mRNA expression levels were determined by qRT-PCR. The Ct values for $h I L-10$ and TLR9 were normalized to the Ct values of the housekeeping gene HMBS. Maximal values of relative $h I L-10 \mathrm{mRNA}$ expression were correlated with the respective relative TLR9 mRNA expression using a two-tailed Pearson's correlation. Shown are the results of a representative experiment out of at least two experiments performed in duplicate (showing mean values)

Table 1 TLR9 single-nucleotide polymorphisms in the five investigated BL-cell lines

\begin{tabular}{|c|c|c|c|}
\hline \multirow[b]{2}{*}{$\begin{array}{l}\text { BL cell } \\
\text { line }\end{array}$} & \multirow[b]{2}{*}{$\begin{array}{l}\text { Epstein-Barr } \\
\text { virus }\end{array}$} & \multicolumn{2}{|c|}{$\begin{array}{l}\text { Single-nucleotide } \\
\text { polymorphism }\end{array}$} \\
\hline & & $\begin{array}{l}\text { rs } 5743836 \\
-1237 \mathrm{~T} / \mathrm{C}\end{array}$ & $\begin{array}{c}\text { rs352140 } \\
2848 \mathrm{G} / \mathrm{A}(\mathrm{P} 545 \mathrm{P})\end{array}$ \\
\hline $\begin{array}{l}\text { Akata } \\
\text { Akata } 31 \\
\text { Ramos } \\
\text { Mutu-I } \\
\text { BJAB }\end{array}$ & $\begin{array}{l}\text { Positive } \\
\text { Negative } \\
\text { Negative } \\
\text { Positive } \\
\text { Negative }\end{array}$ & $\begin{array}{l}\mathrm{T} / \mathrm{T} \\
\mathrm{T} / \mathrm{T} \\
\mathrm{T} / \mathrm{T} \\
\mathrm{T} / \mathrm{C} \\
\mathrm{T} / \mathrm{C}\end{array}$ & $\begin{array}{l}\mathrm{G} / \mathrm{A} \\
\mathrm{G} / \mathrm{A} \\
\mathrm{G} / \mathrm{G} \\
\mathrm{G} / \mathrm{G} \\
\mathrm{G} / \mathrm{G}\end{array}$ \\
\hline
\end{tabular}

\section{Discussion}

We analyzed the effects of TLR9 agonists on BL cell lines as an in vitro model for B-cell tumor. We found that treatment with TLR9 ligands induces distinct cytokine expression and cell death responses in distinct $\mathrm{BL}$ cells. Cell death was (i) dependent on TLR9-MyD88 signaling, (ii) occurred concomitantly with activation and could be suppressed by pan caspase inhibitors, (iii) was not dependent on the presence or absence of EBV in the tumor cells and (iv) was associated with SNPs in the TLR9 gene. Our results suggest that individualized in vitro pretesting of BL responses to $\mathrm{CpG}$ ODNs could help to predict the outcome of therapeutic TLR9 triggering and tailor adjuvant molecular treatment of BL.

Our observation that BL cells of different origin show distinct cell survival following TLR9 triggering is novel. We previously demonstrated that TLR9 triggering counteracts lytic EBV reactivation in $\mathrm{BL}$ cells and promotes latent EBV that is associated with B-cell lymphoproliferation. ${ }^{16}$ Here, we observed CpG type B ODN-induced cell death by apoptosis in EBV-positive Akata and EBV-negative Akata31 cells, but not or to a much lower extent in the other EBV-positive or EBV-negative BL cell lines tested. Thus, the EBV status of the tumor cells does not rule the responses of BL cells to TLR9 triggering.

TLR9-triggered BL cells consistently upregulated hIL-10 expression. hIL-10 influences the development and growth of $\mathrm{B}$ cells $\mathrm{s}^{29}$ and acts as an autocrine growth factor for different B-cell lymphomas. ${ }^{25,26,30}$ Importantly, here, rhIL-10 did 
Table 2 Frequencies of $T L R 9$ single-nucleotide polymorphisms in five BL-cel lines, 15 primary BL tumors and blood samples from 402 healthy individuals

\begin{tabular}{|c|c|c|c|c|}
\hline \multicolumn{5}{|c|}{ Single-nucleotide polymorphism } \\
\hline $\begin{array}{l}\text { rs5743836 } \\
-1237 \mathrm{~T} / \mathrm{C}\end{array}$ & $\begin{array}{c}\text { rs352140 } \\
2848 \mathrm{G} / \mathrm{A} \\
\text { (P545P) }\end{array}$ & $\begin{array}{c}\text { BL cell } \\
\text { lines } \\
N\end{array}$ & $\begin{array}{c}\text { BL } \\
\text { tumors } \\
N(\%)\end{array}$ & $\begin{array}{c}\text { Healthy } \\
\text { individuals } \\
N(\%)\end{array}$ \\
\hline $\mathrm{T} / \mathrm{T}$ & $\mathrm{G} / \mathrm{G}$ & 1 & $4(27)$ & $178(44)$ \\
\hline $\mathrm{T} / \mathrm{T}$ & $\mathrm{G} / \mathrm{A}$ & 2 & $5(33)$ & $165(41)$ \\
\hline$T / T$ & $\mathrm{~A} / \mathrm{A}$ & - & $2(13)$ & - \\
\hline $\mathrm{T} / \mathrm{C}$ & $\mathrm{G} / \mathrm{G}$ & - & - & $1(0)$ \\
\hline T/C & G/A & 2 & $1(7)$ & 55 (14) \\
\hline $\mathrm{T} / \mathrm{C}$ & $\mathrm{A} / \mathrm{A}$ & - & $3(20)$ & $5(1)$ \\
\hline
\end{tabular}

The frequencies of the polymorphisms were statistically not significantly different

neither prevent nor enhance cell death induced by TLR9 triggering. hIL-10, as an anti-inflammatory cytokine, inhibits the Th1 immune response ${ }^{31}$ and this effect would be detrimental in cancer therapy that is based on intact or enhanced immune responses, ${ }^{9}$ as an unintended proliferation of the malignant cells could be provoked. Thus, the function of CpG type B ODN-induced hIL-10 expression in BL cells seems to considerably differ from that in chronic lymphocytic leukemia B cells that were reported to undergo hIL-10mediated apoptosis. ${ }^{10}$

Surprisingly, ODN GpC-2006 induced cell death to the same extent as ODN CpG-2006. ODN GpC-2006 binds to TLR9, but in contrast to CpG-2006 it does not lead to TLR9 signaling in HEK293 cells or to changes in the secondary structure of the ectodomain. ${ }^{32}$ Therefore, we examined whether downstream signaling of TLR9 via MyD88 is involved in the induction of cell death. Indeed, experiments using Akata cells overexpressing a MyD88 dominant-negative mutant indicated that both ODNs induce cell death of BL cells in a MyD88-dependent manner. Others demonstrated that ODNs induce cell death independently of the CpG motif, of TLR ${ }^{33}$ or even of the whole-ODN sequence. ${ }^{34}$ Another pathway that is triggered by CpG ODNs, but is TLR9-independent, was described in monocytes and involves the activation of the Src family kinases Lyn and Hck. ${ }^{35}$ In our experiments, BL cell death induced by TLR9 triggering correlated with increased caspase activity and was caspase-dependent, thus most likely due to apoptosis.

The $\mathrm{BL}$ cell lines tested differed in their TLR9 mRNA expression level and TLR9 SNPs. mRNA expression did not correlate with cell death responses to TLR9 triggering, but the distinct TLR9 SNPs did. The role of TLR9 SNPs in BL is unknown. To start to investigate this we analyzed the frequencies of given SNPS in BL patients and healthy individuals and found them to be similar. A recent report suggests that the rs5743836 polymorphism, which was also detected here, confers an increased risk for non-Hodgkin lymphoma in people from Portugal and Italy but not from the United States. ${ }^{20}$ The association of the C allele rs5743836 with lack of cell death upon TLR9 triggering observed here in the Mutu-I and BJAB BL cell lines is striking. It does not allow establishing a causal link, but justifies the hypothesis that the distinct cell death responses upon CpG ODN treatment in BL cells may be linked to TLR9SNPs. Notably, the $\mathrm{C}$ allele of rs5743836 exhibits greater NF- $\kappa \mathrm{B}$-binding affinity because of an additional NF- $\kappa$ B transcriptional binding site that may lead to increased production of proinflammatory cytokines. ${ }^{36}$ Hence, the presence of the $C$ allele seems to result in enhanced NF- $\kappa \mathrm{B}$ activation following TLR9 triggering. This may lead to protection of ODN CpG treatmentinduced apoptosis that can be observed in BL cells without the $\mathrm{C}$ allele.

In conclusion, therapeutic TLR9 triggering appears to be a double-edge sword that may induce apoptosis, or enhance lymphoproliferation. Our findings suggest that the effect of TLR9 agonists on BL cells should be tested in vitro before installment of therapy and that TLR9 SNPs in BL patients should be evaluated as potential biological markers for the response to treatment targeting innate immunity.

\section{Materials and Methods}

Cell lines. The EBV-positive BL cell lines Akata and Mutu-I, and the EBV-negative BL cell lines Akata 31, BJAB and Ramos were grown in RPMI 1640 supplemented with $10 \%$ heat-inactivated fetal calf serum, streptomycin $(100 \mathrm{mg} / \mathrm{ml})$, penicillin $(100 \mathrm{U} / \mathrm{ml})$ and L-glutamine $(2 \mathrm{mM})$. EBV-positive BL Akata cells expressing a dominant-negative MyD88 (DN-MyD88 Akata) ${ }^{16}$ were grown in

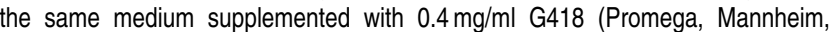
Germany).

Primary BL tissue samples and peripheral blood from healthy individuals. BLs were retrieved from the database of the Institute of Surgical Pathology, University Hospital of Zurich (PathoPro Software, Institute of Medical Software, Saarbrücken, Germany). The BL diagnosis was performed according to the WHO classification of tumors of hematopoietic and lymphoid tissues. ${ }^{37}$ DNA was extracted from paraffin-embedded whole-tissue sections, according to standard procedures. This study was in accordance with Swiss laws and approved by the official authorities of the ethical committee of the Canton of Zurich (StV2-2007). Peripheral blood was collected from 402 healthy blood donors (aged 19-70 years) who were randomly selected according to the criteria of the Swiss Red Cross. ${ }^{38}$

Single-nucleotide polymorphism analysis. Whole-genomic DNA was extracted with the DNeasy Blood and Tissue Kit (Qiagen, Hombrechtikon, Switzerland) according to the manufacturer's instructions. Genotyping of the TLR9 polymorphisms $-1237 \mathrm{~T} / \mathrm{C}$ (rs5743836) and $2848 \mathrm{G} / \mathrm{A}$ (rs352140) was done by tetra-primer assays as previously described. ${ }^{39}$

Treatment with TLR9 agonists. Cells were split to a density of $0.5 \times 10^{6}$ cells/ml. The TLR9 ligands ODN CpG-2216 (type A), ODN CpG-2006 (type B) and ODN GpC-2006 (type B control) were applied at concentrations of $0.5 \mu \mathrm{M}$. ODN (LabForce-InvivoGen, Nunningen, Switzerland) sequences: ODN CpG-2216: $5^{\prime}$-ggGGGACGATCGTCgggggg-3', bases are phosphodiester (capital letters) or phosphorothioate (lower case); ODN CpG-2006: $5^{\prime}$-tcgtcgttttgtcgtttgtcgtt-3', full phosphorothioate backbone; ODN GpC-2006: $5^{\prime}$-tgctgctttgtgctttgtgctt-3', full phosphorothioate backbone.

Microarray analysis. Akata cells were mock treated or treated with CpG2006, and harvested $6 \mathrm{~h}$ later. Total RNA was isolated with RNeasy mini kit (Qiagen) according to the manufacturer's instructions. Microarray analysis was performed at the Functional Genomic Center Zurich (University of Zurich, Zurich, Switzerland). Human Exon 1.0 ST Array chips (Affymetrix, Santa Clara, CA, USA) and Genespring GX software (Agilent Technologies, Basel, Switzerland) were used for the analysis. An at least twofold change in gene expression (upregulation or downregulation) in the treated versus the mock-treated sample was regarded as significant.

qRT-PCR (Taqman). Total RNA was extracted from $10^{6}$ cells with the RNeasy Kit (Qiagen) and DNA was removed with DNA-free (Ambion Europe, Huntingdon, Cambridgeshire, UK). $1 \mu \mathrm{g}$ of the purified RNA was used to generate cDNA with the High-Capacity cDNA Reverse Transcription Kit (Applied Biosystems, 
Rotkreuz, Switzerland). Quantitative real-time PCR was performed with specific Taqman primers and probes on ABI 7200 (Applied Biosystems). Data were analyzed with the software SDS2.2 (Applied Biosystems). Delta cycle threshold (Ct) values for the respective genes were normalized to HMBS.

Staining for surface antigens. $10^{5}$ cells were stained with FITC mouse anti-human IgM (Clone G20-127), PE-Cy5 mouse anti-human IgG (Clone G18-145), PE mouse anti-human IgD (Clone IA6-2) or the respective isotype controls, FITC IgG1 $\kappa$ isotype control (Clone MOPC-21), PE-Cy5 mouse IgG1 $\kappa$ isotype control (Clone MOPC-21), PE mouse IgG2a $\kappa$ isotype control (Clone G155178) or PE-Cy5 anti-human CD40 (Cat. 555590) (all from BD Biosciences, Allschwil, Switzerland) for $30 \mathrm{~min}$ at $4{ }^{\circ} \mathrm{C}$ in the dark. Cells were counted with a flow cytometer (FACSCanto II, BD Biosciences).

Annexin V/7-AAD staining. To assess apoptotic, necrotic or dead and viable cells, $10^{5}$ cells were harvested, washed with phosphate-buffered saline (PBS) and resuspended in $100 \mu \mathrm{l}$ Annexin $\mathrm{V}$ binding buffer (140 mM NaCl, $2.5 \mathrm{mM}$ $\mathrm{CaCl}_{2}, 10 \mathrm{mM}$ HEPES, pH 7.4) and incubated with $5 \mu$ l Annexin $\mathrm{V}$ and $5 \mu \mathrm{l}$ 7-AAD (BD Biosciences) for $15 \mathrm{~min}$ at room temperature in the dark. After addition of $200 \mu$ l Annexin V binding buffer, cells were analyzed with the FACSCanto II flow cytometer (BD Biosciences).

Propidium lodide staining. To discern between dead and viable cells, treated cells were stained with $50 \mu \mathrm{g} / \mathrm{ml} \mathrm{PI} \mathrm{(Sigma-Aldrich} \mathrm{Chemie} \mathrm{GmbH,} \mathrm{Buchs,}$ Switzerland) for $15 \mathrm{~min}$ at room temperature and then analyzed with the FACSCanto II flow cytometer (BD Biosciences).

Protein isolation, quantification and Western blot. Total protein lysates were obtained after lysing the cells in RIPA complete buffer $(50 \mathrm{mM}$ Tris- $\mathrm{HCl}$ pH 7.5, $150 \mathrm{mM} \mathrm{NaCl}, 2 \mathrm{mM}$ EDTA, $1 \% \mathrm{NP} 40$ complemented with $0.1 \%$ SDS, $1 \times$ EDTA-free protease inhibitor cocktail (Roche, Rotkreuz, Switzerland)). Cell extracts were passed 10 times through a $25-G$ syringe. Protein content was determined using the Pierce BCA Protein Assay Kit (ThermoScientific, Erembodegem, Belgium), according to the manufacturer's instructions. To analyze protein expression by western blot, protein $(20 \mu \mathrm{g} / \mathrm{well})$ was loaded into a NuPAGE 4-12\% Bis-Tris Gel (life technologies, Zug, Switzerland) and subjected to SDS-PAGE electrophoresis, transferred electrophoretically to a nitrocellulose membrane (GE Healthcare, Glattbrugg, Switzerland), incubated with rabbit antiPARP antibody or rabbit anti- $\beta$-Actin antibody, and subsequently with anti-rabbit IgG, HRP-linked antibody (all diluted 1:1000 and from, Cell Signaling Technology (Allschwil, Switzerland). The signal was detected with the ECL Western Blotting Detection Reagents (GE Healthcare) and imaged using the LAS-3000 (Fujifilm, Dielsdorf, Switzerland) and image reader LA-3000 (Fujifilm).

hIL-10 ELISA. hIL-10 protein concentrations were determined in supernatants from TLR9-stimulated cultures by standard capture ELISA (ReadySET-Go, eBioscience, Vienna, Austria) according to the manufacturer's instructions Plates were read at $450 \mathrm{~nm}$ once the substrate had developed, and cytokine concentration was determined by extrapolation from the standard curve.

Caspase-3/7 activity. Activity of caspase-3/7 was assessed with the Caspase-Glo 3/7 Assay according to the manufacturer's protocol (Promega, Wallisellen, Switzerland). Cells, dispensed at $0.5 \times 10^{6} \mathrm{cells} / \mathrm{ml} / \mathrm{well}$ in a 24-well plate were treated with TLR9 ligands and incubated at $37^{\circ} \mathrm{C}$ for $48 \mathrm{~h}$. At the end of the incubation period, $100 \mu \mathrm{l}$ of Caspase-Glo 3/7 reagent was added to $100 \mu \mathrm{l}$ cell suspension in a white-walled 96-well plate and incubated at room temperature for $1 \mathrm{~h}$. Luminescence intensity was determined using a Synergy HT Multi-Detection Microplate Reader (BioTek, Luzern, Switzerland).

Treatment of BL cells with rhIL-10. One day before the experiment, the cells were split to a density of $0.5 \times 10^{6}$ cells $/ \mathrm{ml}$. The next day, $10^{6}$ cells were incubated with $900 \mathrm{pg}$ rhlL-10/ml (Immunotools, Friesoythe, Germany) for the indicated time points. This concentration corresponds to the hIL-10 protein concentration induced by ODN CpG-2006 in Akata cells. ${ }^{16}$

\section{Conflict of Interest}

The authors declare no conflict of interest.
Acknowledgements. This work was funded by the Swiss National Foundation (310040-114118), Oncosuisse and the Cancer League of the Canton of Zurich.

1. Iwasaki A, Medzhitov R. Toll-like receptor control of the adaptive immune responses. Nat Immunol 2004; 5: 987-995.

2. Chiron D, Bekeredjian-Ding I, Pellat-Deceunynck C, Bataille R, Jego G. Toll-like receptors: lessons to learn from normal and malignant human B cells. Blood 2008; 112: 2205-2213.

3. Rifkin IR, Leadbetter EA, Busconi L, Viglianti G, Marshak-Rothstein A. Toll-like receptors, endogenous ligands, and systemic autoimmune disease. Immunol Rev 2005; 204: 27-42.

4. Bourke E, Bosisio D, Golay J, Polentarutti N, Mantovani A. The toll-like receptor repertoire of human B lymphocytes: inducible and selective expression of TLR9 and TLR10 in normal and transformed cells. Blood 2003; 102: 956-963.

5. Dorner M, Brandt S, Tinguely M, Zucol F, Bourquin JP, Zauner L et al. Plasma cell toll-like receptor (TLR) expression differs from that of $B$ cells, and plasma cell TLR triggering enhances immunoglobulin production. Immunology 2009; 128: 573-579.

6. Hornung V, Rothenfusser S, Britsch S, Krug A, Jahrsdorfer B, Giese T et al. Quantitative expression of toll-like receptor 1-10 mRNA in cellular subsets of human peripheral blood mononuclear cells and sensitivity to CpG oligodeoxynucleotides. J Immunol 2002; 168: $4531-4537$.

7. Vollmer J, Krieg AM. Immunotherapeutic applications of CpG oligodeoxynucleotide TLR9 agonists. Adv Drug Deliv Rev 2009; 61: 195-204.

8. Weiner GJ. CpG oligodeoxynucleotide-based therapy of lymphoid malignancies. Adv Drug Deliv Rev 2009; 61: 263-267.

9. Krieg AM. Toll-like receptor 9 (TLR9) agonists in the treatment of cancer. Oncogene 2008; 27: 161-167.

10. Liang X, Moseman EA, Farrar MA, Bachanova V, Weisdorf DJ, Blazar BR et al. Toll-like receptor 9 signaling by $\mathrm{CpG}-\mathrm{B}$ oligodeoxynucleotides induces an apoptotic pathway in human chronic lymphocytic leukemia B cells. Blood 2010; 115: 5041-5052.

11. Jahrsdorfer B, Muhlenhoff L, Blackwell SE, Wagner M, Poeck H, Hartmann E et al. B-cell lymphomas differ in their responsiveness to $\mathrm{CpG}$ oligodeoxynucleotides. Clin Cancer Res 2005; 11: 1490-1499.

12. Decker T, Schneller F, Sparwasser T, Tretter T, Lipford GB, Wagner $H$ et al. Immunostimulatory CpG-oligonucleotides cause proliferation, cytokine production, and an immunogenic phenotype in chronic lymphocytic leukemia B cells. Blood 2000; 95: 999-1006.

13. Huang B, Zhao J, Li H, He KL, Chen Y, Chen SH et al. Toll-like receptors on tumor cells facilitate evasion of immune surveillance. Cancer Res 2005; 65: 5009-5014.

14. Wolska A, Lech-Maranda E, Robak T. Toll-like receptors and their role in carcinogenesis and anti-tumor treatment. Cell Mol Biol Lett 2009; 14: 248-272.

15. Ladell K, Dorner M, Zauner L, Berger C, Zucol F, Bernasconi M et al. Immune activation suppresses initiation of lytic Epstein-Barr virus infection. Cell Microbiol 2007; 9 2055-2069.

16. Zauner L, Melroe GT, Sigrist JA, Rechsteiner MP, Dorner M, Arnold M et al. TLR9 triggering in Burkitt's lymphoma cell lines suppresses the EBV BZLF1 transcription via histone modification. Oncogene 2010; 29: 4588-4598.

17. Young LS, Rickinson AB. Epstein-Barr virus: 40 years on. Nat Rev Cancer 2004; 4: 757-768.

18. Rickinson A, Kieff E. Epstein-Barr virus. In: Knipe DM (ed) Fields Virology. 4th edn Lippincott Williams \& Wilkins: Philadelphia, PA, 2001; pp 2575-2627.

19. Traggiai E, Becker S, Subbarao K, Kolesnikova L, Uematsu Y, Gismondo MR et al. An efficient method to make human monoclonal antibodies from memory $B$ cells: potent neutralization of SARS coronavirus. Nat Med 2004; 10: 871-875.

20. Carvalho A, Cunha C, Almeida AJ, Osorio NS, Saraiva M, Teixeira-Coelho $M$ et al. The rs5743836 polymorphism in TLR9 confers a population-based increased risk of nonHodgkin lymphoma. Genes Immun 2012; 13: 197-210.

21. Peng SL. Signaling in B cells via Toll-like receptors. Curr Opin Immunol 2005; 17: 230-236.

22. Jahrsdorfer B, Hartmann G, Racila E, Jackson W, Muhlenhoff L, Meinhardt G et al. CpG DNA increases primary malignant $B$ cell expression of costimulatory molecules and target antigens. J Leukoc Biol 2001; 69: 81-88.

23. Jenkins PJ, Binne UK, Farrell PJ. Histone acetylation and reactivation of Epstein-Barr virus from latency. J Virol 2000; 74: 710-720.

24. Moore KW, de Waal Malefyt R, Coffman RL, O'Garra A. Interleukin-10 and the interleukin10 receptor. Annu Rev Immunol 2001; 19: 683-765.

25. Beatty PR, Krams SM, Martinez OM. Involvement of IL-10 in the autonomous growth of EBV-transformed B cell lines. J Immunol 1997; 158: 4045-4051.

26. Jones KD, Aoki Y, Chang Y, Moore PS, Yarchoan R, Tosato G. Involvement of interleukin10 (IL-10) and viral IL-6 in the spontaneous growth of Kaposi's sarcoma herpesvirusassociated infected primary effusion lymphoma cells. Blood 1999; 94: 2871-2879.

27. Ng MT, Van't Hof R, Crockett JC, Hope ME, Berry S, Thomson J et al. Increase in NF-kappaB binding affinity of the variant $C$ allele of the toll-like receptor $9-1237 \mathrm{~T} / \mathrm{C}$ polymorphism is associated with Helicobacter pylori-induced gastric disease. Infect Immun 2010; 78: 1345-1352.

28. Soriano-Sarabia N, Vallejo A, Ramirez-Lorca R, Rodriguez Mdel M, Salinas A Pulido I et al. Influence of the Toll-like receptor $91635 \mathrm{~A} / \mathrm{G}$ polymorphism on the CD4 count, HIV viral load, and clinical progression. JAIDS 2008; 49: 128-135. 
29. Rousset F, Garcia E, Defrance T, Peronne C, Vezzio N, Hsu DH et al. Interleukin 10 is a potent growth and differentiation factor for activated human B lymphocytes. Proc Natl Acad Sci USA 1992; 89: 1890-1893.

30. Masood R, Zhang Y, Bond MW, Scadden DT, Moudgil T, Law RE et al. Interleukin-10 is an autocrine growth factor for acquired immunodeficiency syndrome-related B-cell lymphoma. Blood 1995; 85: 3423-3430.

31. Saraiva M, O'Garra A. The regulation of IL-10 production by immune cells. Nat Rev Immunol 2010; 10: 170-181.

32. Latz E, Verma A, Visintin A, Gong M, Sirois CM, Klein DC et al. Ligand-induced conformational changes allosterically activate Toll-like receptor 9. Nat Immunol 2007; 8: 772-779.

33. Grauer OM, Molling JW, Bennink E, Toonen LW, Sutmuller RP, Nierkens S et al. TLR ligands in the local treatment of established intracerebral murine gliomas. J Immunol 2008; 181: $6720-6729$.

34. Castro JE, Prada CE, Aguillon RA, Kitada S, Fukuda T, Motta M et al. Thymidinephosphorothioate oligonucleotides induce activation and apoptosis of CLL cells independently of CpG motifs or BCL-2 gene interference. Leukemia 2006; 20: 680-688.

35. Sanjuan MA, Rao N, Lai KT, Gu Y, Sun S, Fuchs A et al. CpG-induced tyrosine phosphorylation occurs via a TLR9-independent mechanism and is required for cytokine secretion. J Cell Biol 2006; 172: 1057-1068.
36. Ng MT, Van't Hof R, Crockett JC, Hope ME, Berry S, Thomson J et al. Increase in NFkappaB binding affinity of the variant $C$ allele of the toll-like receptor $9-1237 \mathrm{~T} / \mathrm{C}$ polymorphism is associated with Helicobacter pylori-induced gastric disease. Infect Immun 2010; 78: 1345-1352

37. Swerdlow SH, Campo E, Harris NL, Jaffe ES, Pileri SA, Stein H et al. WHO Classification of Tumours of Haematopoietic and Lymphoid Tissues. IARC: Lyon, 2008.

38. Muntwyler J, Marti-Jaun J, Luscher TF, Hanseler E, Hersberger M. The Asp298 but not the C-786 genotype of the endothelial nitric oxide synthase is reduced with age in healthy Swiss men. Clin chem lab med: CCLM/FESCC 2005; 43: 971-973.

39. Krayenbuehl PA, Hersberger M, Truninger K, Mullhaupt B, Maly FE, Bargetzi M et al. Tolllike receptor 4 gene polymorphism modulates phenotypic expression in patients with hereditary hemochromatosis. Eur J Gastroenterol Hepato 2010; 22: 835-841.

Cell Death and Disease is an open-access journal published by Nature Publishing Group. This work is licensed under the Creative Commons Attribution-NonCommercial-No Derivative Works 3.0 Unported License. To view a copy of this license, visit http://creativecommons.org/licenses/by-nc-nd/3.0/

Supplementary Information accompanies the paper on Cell Death and Disease website (http://www.nature.com/cddis) 